\title{
Videoactivismo: revisión conceptual y práctica del fenómeno
}

\section{Videoativismo: revisão conceitual e prática do fenômeno}

\author{
Ana Lúcia Nunes de SOUSA ${ }^{1}$
}

\section{Resumen}

Este trabajo objetiva comprender el videoactivismo a partir de su concepto y de sus prácticas contemporáneas alrededor del mundo, pasando por Túnez, Egipto, España, Estados Unidos, Turquía y Brasil. Para tal, esta investigación se ha basado en una revisión bibliográfica, además de la investigación participativa en la ciudad de Río de Janeiro. Nuestro estudio sugiere que el videoactivismo se materializa en una variedad de formatos y géneros, presentándose como una importante actividad para los movimientos sociales. En todos los casos analizados, el videoactivismo estuvo vinculado a las redes sociales, principalmente YouTube y Facebook. Pese a que haya sido muy popular durante las protestas, esta investigación demuestra que la producción videoactivista fue una tarea específica, limitada a un número reducido de activistas.

Palabras-clave: videoactivismo; concepto; práctica; movimientos sociales; redes sociales.

\section{Resumo}

Este trabalho busca compreender o videoativismo a partir de seu conceito e práticas contemporâneas ao redor do mundo, passando por Tunísia, Egito, Espanha, Estados Unidos, Turquia e Brasil. Para isso, o estudo se baseia em uma revisão bibliográfica, além de uma investigação participativa na cidade do Rio de Janeiro. Sugerimos que o videoativismo se materializa em uma variedade de formatos e gêneros, apresentando-se como uma atividade importante para os movimentos sociais. Em todos os casos analisados, o videoativismo esteve vinculado às redes sociais, principalmente o YouTube e o Facebook. Embora muito popular durante os protestos, a investigação demonstra que a produção de videoativistas foi uma tarefa específica, limitada a um número reduzido de ativistas.

Palavras-chave: videoativismo; conceito; prática; movimentos sociais; redes sociais.

\footnotetext{
${ }^{1}$ Professora adjunta no Instituto Nutes de Educação em Ciências e Saúde da Universidade Federal do Rio de Janeiro, com atuação no Programa de Pós-graduação em Educação em Ciências e Saúde e no Laboratório de Vídeo Educativo. E-mail: anabetune@gmail.com.
} 


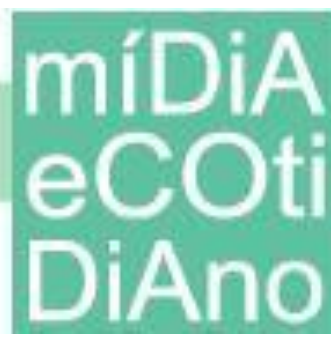

\section{Introducción}

Los movimientos sociales tienen en la comunicación una de sus principales actividades de apoyo y construcción colectiva. Sensibilizar la sociedad para que "considere sus protestas no como acontecimientos aislados, sino como parte de una exigencia razonable (de tener razón) de justicia" (SANCHO, 2015, p.83) es una tarea fundamental. Según Gitlin (1980), los grandes medios informativos, históricamente, vienen representando a los movimientos sociales a través de un enfoque negativo. La cobertura tiende a optar por encuadres más episódicos que temáticos, enfocado en eventos específicos, como actos individuales de violencia (WALLACK et al. ,1993). Este tipo de cobertura compone un "paradigma mediático" para abordar la protesta social, o sea, son utilizadas "rutinas estandarizadas o implícitas para cubrir la protesta social" (MCLEOD; HERTOG, 1999, p. 310), "atribuyendo diferentes relaciones de causa y efecto a las protestas civiles y les asignan varios grados de apoyo" (MAN CHAN; LEE, 1984, p.188). La ideología y las prácticas de los movimientos sociales acaban por ser simplificadas y homogeneizadas en este tipo de enfoque (ATTON, 2003). Esta es una de las razones por las cuales muchos movimientos crean sus medios, haciendo surgir grupos dedicados a hacer otro tipo de comunicación, como es el caso del video activismo contemporáneo, objeto de análisis en este trabajo.

Es importante recordar que los movimientos sociales han tratado de construir sus propios medios desde el surgimiento de las tecnologías de la información, incluyendo la prensa escrita, la radio o el cine, y no solamente los avances más actuales. A partir de 1980, el número y diversidad de estos proyectos creció aún más alrededor del mundo, principalmente las radios y televisoras comunitarias. Hoy en día, la vida de las personas está cada vez más en contacto con "varias formas de resistencia en los medios de comunicación, sea como lectores, audiencias y productores" (COYER et al., 2007, p.1).

El videoactivismo puede ser considerado una de las facetas de la resistencia en los medios de comunicación. Este activismo mediático a través de las redes y medios se popularizó en los últimos años. El poder de la imagen unida a la penetración de las redes sociales online ha sido una de las formas comunicativas más exploradas durante el ciclo de protestas contemporáneas, iniciada en el 2011, en el norte de África. Los vídeos con millones de visitas en YouTube se viralizaron a través de Facebook y Twitter, 


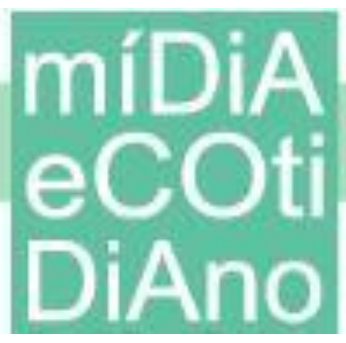

haciendo que las imágenes de las protestas fuesen revividas en la red, y hasta cierto punto estimulando a que más y más personas se sumaran a las protestas callejeras.

En este trabajo nos volcamos a dos objetivos interconectados: comprender el videoactivismo desde su punto de vista conceptual y desde sus prácticas contemporáneas, enfocando en cómo se desarrolló en el reciente ciclo de protestas, pasando por Túnez, Egipto, España, Estados Unidos y Turquía, hasta llegar a Brasil. Para tal, esta investigación se ha basado en una revisión bibliográfica del concepto y práctica del video activismo, revisitando las principales obras teóricas y sistematización de experiencias realizadas en los últimos años, buscando ofrecer una mirada amplia sobre el fenómeno. Además, de la investigación participativa realizada en la ciudad de Río de Janeiro, junto a los colectivos de videoactivismo que actuaron durante las protestas en el contexto del Mundial de Fútbol de la FIFA, en el 2014.

\section{Videoactivismo: recorrido histórico y conceptual}

El videoactivismo como una práctica comunicativa junto a los movimientos sociales tiene un largo recorrido, que se remite al inicio del cine (MATEOS; GAONA, 2015). El ideal videoactivista de "reportear la revolución, filmar y denunciar, transferir protagonismo a los que no son poder" (MATEOS; GAONA, 2015, p. 109) puede ser rastreado en una serie de prácticas audiovisuales como: 1) El cine documental social desde sus primeros tiempos; 2) El cine latinoamericano de los años 1960; el American Cinema Group; el movimiento Newsreel en Estados Unidos y el cine underground americano; 3) El movimiento de audiovisual popular y comunitario, que se expresó con mucha fuerza en los años 1980, a través de la creación de televisoras comunitarias; 4) Los movimientos de media activismo nacidos a la luz de las luchas antiglobalización de los años 90, principalmente el Centro de Medios Independientes - Indymedia; 5) El videoactivismo online, popularizado en las revueltas contemporáneas, como el Occupy Wall Street, en EEUU; el 15M/Indignadas, en España; las luchas anti-austeridad, en Europa; las revueltas en el norte de África; y el Occupy Park Gezi, en Turquía.

En el pasado, las imágenes producidas por el videoactivismo solían estar destinadas a proyecciones privadas, muchas veces dentro del propio movimiento; y a algunas proyecciones públicas, principalmente aquellas realizadas por las telestreet; y, en 


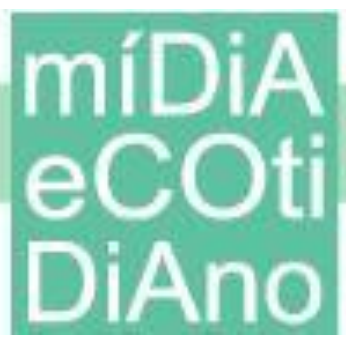

algunos casos llegaban a ser transmitidas por cable o TV abierta en los canales comunitarios. Las rutinas productivas videoactivistas empezaron a cambiar profundamente durante las protestas en Seattle (1999), cuando la conexión entre vídeo e Internet fue utilizada, por primera vez, a gran escala. Desde entonces, la conjunción entre la alta penetración de estos dispositivos en la sociedad, la conectividad constante y las redes sociales virtuales promovieron cambios significativos en las prácticas comunicativas y sociales (WELMMAN; RAINIE, 2013), y en el videoactivismo en particular. El acceso de una amplia variedad de personas a dispositivos móviles capaces de filmar y de conectarse a Internet, cada vez con mayor calidad en la imagen, también está introduciendo importantes cambios en el proceso. Con un teléfono móvil y conocimientos básicos de grabación, montaje y upload o streaming, se ha ampliado el número de ciudadanos que pueden utilizar el vídeo como herramienta para luchar por justicia social.

Así, hoy día las protestas urbanas suelen filmarse a cada minuto, en cada centímetro de la ciudad, por un ejército de videoactivistas (PASQUINELLI, 2002); se transmiten en vivo vía streaming y se comparten en redes sociales online. Estas plataformas han significado un cambio en las estructuras de producción y circulación de las imágenes realizadas por el videoactivismo. Como espacios gratuitos para alojamiento y distribución, acabaron apropiados por diversos movimientos sociales que no tenían acceso a los grandes medios, posibilitando la distribución de contenidos a un público global. El videoactivismo contemporáneo está, debido a esto, trasladándose cada vez más al terreno virtual.

Así como ocurre con las prácticas comunicativas vinculadas a los movimientos sociales de una forma más general, cuando se aborda el vídeo es posible encontrar relatos de experiencias diversas y la utilización de distintos conceptos para nombrarlas, como: vídeo participativo (LUNCH; LUNCH, 2006; SHIRLEY, 2003; JOHANSSON, 1999), vídeo para el desarrollo, vídeo radical, vídeo alternativo, vídeo comunitario, vídeo guerrilla, advocacy vídeo, (ASKANIUS, 2014; PASQUINELLI, 2002), audiovisual de combate (BUSTOS, 2006) etc.

Este trabajo se centra, a nivel conceptual, en el videoactivismo, por más que en la literatura especializada no se haya llegado a una terminología homogénea para 


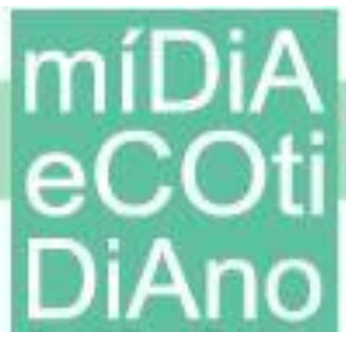

definirlo (MATEOS; RAJAS, 2014). Harding (2001), Widgington (2005) y Mateos y Rajas (2014) presentan un concepto bastante ampliado, siendo que Harding (2001) argumenta que el videoactivista utiliza el vídeo como una herramienta táctica para luchar por la justicia social, haciendo de la cámara un poderoso instrumento político. Según él, puede haber varios tipos de videoactivistas, pero todos entienden el poder de la imagen y hacen uso de este poder para cambiar sus comunidades (HARDING, 2001.). Para Widgington (2005), el videoactivista está involucrado en el activismo diariamente, utiliza la cámara para abogar por justicia y el cambio social y desarrolla una relación de proximidad y apoyo con la comunidad. Mateos y Rajas (2014) se centran en el videoactivismo como proceso, identificándolo con las prácticas utilizadas como recursos de intervención política por actores subalternos con finalidad transformadora.

Otras corrientes, sin embargo, se centran en aspectos más específicos para aproximarse al concepto. Zarzuelo (2012) se orienta respecto a la posición del videoactivista en la contienda. Para esta investigadora, el videoactivista está dentro de la acción colectiva, es protagonista y forma parte de ella como un militante más. Wilson y Tanya (2010) llaman videoactivista a personas que utilizan el vídeo como herramienta táctica para frenar la violencia policial, documentar abusos y otras conductas policiales o de las autoridades, y así intentar influenciar la agenda política. Para Pasquinelli (2002), el videoactivismo nace de la imposibilidad de ser parte de los medios masivos. A través de sus propias cámaras, los activistas pueden evitar las omisiones y manipulaciones por parte de los grandes medios, utilizando las tecnologías para tal fin.

Este breve recorrido teórico apunta a que la literatura académica considera el posicionamiento político como factor fundamental a la hora de definir los procesos de videoactivismo. Mateos y Rajas (2014), incluso, llaman la atención sobre el hecho de que lo más importante para explicarlo es el tipo de práctica, el proceso, y no el producto. Así, dentro de la categoría o concepto de videoactivismo se pueden incluir prácticas muy diversas, en diferentes géneros y formatos, que se dan a conocer en diferentes plataformas, como los cines foros, talleres de formación audiovisual, las telestreet, proyecciones vídeo artísticas, producción de vídeos y cine, informes audiovisuales, transmisiones en directo de protestas, etc. 
En este trabajo, se parte desde la amplia noción de videoactivismo aplicada por Harding (2001), pero con mayor interés especialmente por un videoactivismo muy particular: aquel desarrollado entre la calle y los medios sociales en Internet. Las imágenes videoactivistas que nos llaman la atención son aquellas que se viralizaron en el ciclo reciente de protestas. Entendemos que estas imágenes no pueden ser analizadas sin considerar su vinculación global. Por consiguiente, en los próximos puntos se analizará lo que se considera como los referentes más contundentes en el videoactivismo contemporáneo, desde el norte de África a Brasil.

\section{Videoactivismo en las protestas contemporáneas en el norte de África}

Las protestas emergidas en el norte africano, conocidas como "Primavera Árabe”, convulsionaron el mundo a través de los vídeos virales de autoinmolación, de violencia policial y de la amplitud de las protestas callejeras que comenzaron en la región a partir del 2011. Fue la primera señal evidente de que el vídeo activismo online, filmado y compartido a través desde las redes sociales, cobraría importancia fundamental en las protestas contemporáneas.

El 17 de diciembre de 2010, en Túnez, el cuñado de Mohamed Bouazizi — el joven tunecino que se auto inmoló tras haber tenido su puesto de venta ambulante confiscado por oficiales municipales - subió a Facebook un vídeo de protesta de la madre del joven. El material fue compartido por Al Jazeera y se viralizó entre los usuarios de Facebook y de Twitter. Rápidamente, los hashtags mencionando a Bouazizi y la necesidad de cambiar el país, tomaron el ciberespacio y llegaron a las calles (HALVERSON et al., 2013; HOWARD et al., 2011).

Pero fue durante las protestas en Egipto que el videoactivismo tomó mayores proporciones. Otra vez se tiene el vídeo online como la chispa que encendió el prado. En 2010, empezaron a circular vídeos en YouTube, cuestionando la muerte del joven Khaleed Saeed, en una comisaría de policía (HALVERSON et al., 2013). El 18 de enero del 2011, la activista Asmma Mafouz, publicó un vídeo, en Facebook y YouTube, llamando a todos los egipcios a protestar en contra del gobierno. El vídeo llegó al New York Times, The Washington Post y varios otros grandes medios informativos (WALL; 
EL ZAHED, 2011) y se viralizó en las redes sociales online. Asmma publicó más tres vídeos en enero, que fueron seguidos por grandes protestas callejeras.

El videoactivismo online en Egipto se transformó rápidamente en un fenómeno popular, apropiado por ciudadanos y activistas. Snowden (2016) relata que, en varios vídeos sobre las protestas disponibles en YouTube, es común escuchar la voz de manifestantes pidiendo que las acciones fuesen filmadas, principalmente cuando se trataba de violencia policial. Un vídeo, filmado desde un balcón, el 25 de enero, muestra como la policía reprimía la protesta utilizando un tanque para dispersar con agua a los manifestantes. Este vídeo, "Egyptian Tank Man - فتى المدرعة المصري", que tiene más de tres millones de visitas en YouTube, es el vídeo más visitado durante los 18 días de protesta en el país. Otro vídeo significativo fue filmado también el 25 de enero, "Protest in Egypt - Jan 25, 2011” y muestra, desde un balcón, millares de manifestantes llegando a la Plaza Tahir (HOWARD et al., 2011). En un estudio sobre los vídeos más virales durante las protestas en Egipto, Howard et al., (2011) apunta los cuatro contenidos con mayor relevancia presentes en estos materiales audiovisuales: imágenes sin edición de las protestas y movilizaciones; comentarios de los ciudadanos sobre las protestas; comentarios de expertos sobre la situación política y "bandas sonoras para la revolución" (p.22). Siendo esta última categoría la que más visualizaciones obtuvo durante las manifestaciones.

El streaming de las protestas también fue suficientemente utilizado por los videoactivistas y ciudadanos egipcios. En su mayor parte, utilizaron la plataforma Bambuser para transmitir las protestas, que fue cerrada por Mubarak luego de también cerrar a Facebook y Twitter. Para Krona (2015), los videoactivistas egipcios crearon una narrativa agregada de la rebelión. La transmisión por streaming tuvo un carácter estratégico generador de confiabilidad al relato y conexión de los manifestantes con la comunidad egipcia en la diáspora. Cuando la propia policía empezó a hacer uso de la plataforma como herramienta de contravigilancia, los videoactivistas tuvieron que adaptarse, cambiando sus formas de utilización, deshabilitando la función de geolocalización y filmando de forma más neutral.

En la literatura académica queda patente que el videoactivismo cobró su papel más importante en Egipto. Pero Eyzaguiree y El Azrak (2015) inscriben que la práctica 


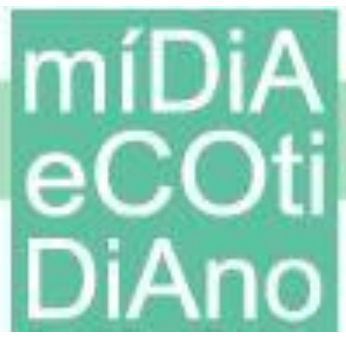

también fue largamente utilizada en otros países, principalmente en Siria y Marruecos. En este último, los activistas del Movimiento 20 de febrero, liderado por jóvenes, utilizaron el vídeo para hacer un llamado a todos los marroquíes a que tomaran las calles y realizaran una semana de acción política.

\section{Videoactivismo en el 15M/Indignadas}

El videoactivismo también fue un elemento importante en el desarrollo del movimiento 15M, en España. Monterde (2015) apunta que, desde el primer intento de acampar en Puerta de Sol, en Madrid, el 15 de mayo de 2012, el audiovisual fue "pieza fundamental para dar visibilidad pública de las actividades en las acampadas frente al cierre mediático de sus primeros días" (p. 269). Durante la primera gran manifestación realizada por el 15M, en más de 60 ciudades, el streaming en vivo y en directo fue una de las formas más exitosas de vincularse encontrada por los activistas (MONTERDE, 2015). Los vídeos colgados a YouTube y compartidos en Twitter y Facebook y el streaming en vivo, fueron las principales herramientas utilizadas en el videoactivismo durante el movimiento. Así, se hacían públicas no solo las demandas del movimiento y la represión policial, pero también las asambleas, que solían ser "retransmitidas por streaming o grabadas en vídeo y subidas a la red" (MONTERDE, 2015, p. 201).

Pese al papel del audiovisual que, según Alabao (2014), cumplía el papel de “informar, denunciar, retratar, convocar a manifestaciones o movilizar adhesión” (p. 55), no todas las personas que participaron en el $15 \mathrm{M}$ se convirtieron en videoactivistas. Esta era, más bien, una actividad muy especializada llevada a cabo por personas específicas y que, de acuerdo con una encuesta realizada por Monterde (2015), abarcaba el 11,6\% de los participantes del movimiento.

Cuando se aborda específicamente el caso de las transmisiones por streaming, Rioja (2014) afirma que desde “Tomalaplaza.net", en el inicio de las movilizaciones, se publicó una guía técnica de trasmisión y se realizó un llamado a que todos actuasen como reporteros populares de la protesta, utilizando sus móviles para transmitir. Pero tanto Rioja (2014) como Monterde (2015) coinciden en que la mayor parte de las cuentas de streaming, vinculadas a alguna actividad del $15 \mathrm{M}$, fueron abiertas en medio de las acampadas. Rioja (2014) analizó todas las cuentas de streaming catalogadas en 
15Mpedia, de las cuales solamente tres cuentas habían sido creadas en 2011, al inicio de las acampadas. Aquí caben destacar tres aspectos: 1) el alto coste del streaming, siendo necesario un teléfono móvil con cámara de alta calidad y acceso a Internet rápida, dificultando la extensión de la práctica; 2) y quizás, lo más importante, la tendencia a la utilización de cuentas colectivas vinculadas a la red formada en el proprio 15M, que, según Monterde (2015), representaba el 70\% de las cuentas activas.

En España, en la mayor parte de los casos, cada acampada tenía su propia comisión de comunicación, responsable por recoger el material y difundirlo colectivamente. Así, cada acampada, como la de Barcelona y Madrid, por ejemplo, tenía su propia comisión audiovisual, de las cuales surgieron "acampadabcntv", "latele.cat" y "15M BCN TV". A parte, también fue importante la cobertura audiovisual realizada desde canales que, si bien eran profesionales, no dejaban de ser "alternativos", como "Periodismo Humano", cuya trasmisión vía streaming de la segunda jornada de lucha en Puerta de Sol, en Madrid, fue apropiada por el Washington Post, obligando a los grandes medios de comunicación de todo el mundo a reportarla (RIOJA, 2014). Por otro lado, también estuvo la cobertura de "Toma la Tele" ${ }^{5 "}$; la formación de la red Peoplewitness, una red de streamers formada en el seno del 15M, tras un taller ofrecido por activistas mediáticos del Occupy Wall Street, en 2012, en Barcelona (MONTERDE, 2015); y la realización del documental $15 \mathrm{~m} . c c$, que empezó con aspiraciones de ser una pieza colectiva, lo que al final no fue totalmente alcanzado (SÁNCHEZ; MENA, 2015), pero aun así es una importante obra videoactivista acerca del movimiento. Si bien muchos ciudadanos realizaron labores videoactivistas durante las protestas, la literatura académica apunta que fueron las iniciativas a nivel colectivo, sea desde las propias acampadas, las redes alternativas ya existentes y las que se formaron a partir del 15M, las que tuvieron más peso en el desarrollo del movimiento.

\footnotetext{
${ }^{2}$ Recuperado de < http://www.ustream.tv/channel/acampadabcn2> Acceso en el 10 de mayo del 2017.

${ }^{3}$ Recuperado de <http://www.youtube.com/user/15Mbcn> Acceso en el 10 de mayo del 2017.

${ }^{4}$ Periódico fundado en el 2010, sin ánimo de lucro, en forma de cooperativa, basado en donaciones. http://sociedad.elpais.com/sociedad/2010/03/22/actualidad/1269212404_850215.html

5 Toma la Tele se origina en marzo de 2012 y se plantea como un magazine audiovisual de información crítica. Es transmitido por Internet y en la televisión local de Madrid (Salinas, 2014).
} 


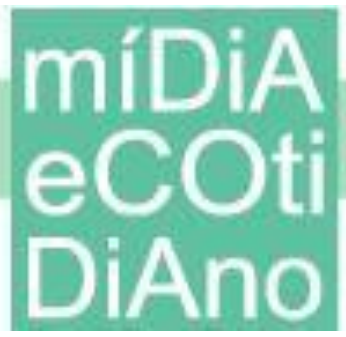

\section{Videoactivismo en el Occupy Wall Street}

Durante el Occupy Wall Street (OWS) se experimentaron prácticas en torno al videoactivismo muy diversas. Thorson et al. (2013) en una investigación sobre los vídeos que abordaban el movimiento en Twitter y YouTube, han catalogado más de 50 mil materiales audiovisuales, de entre ellos vídeos virales que reportaban casos de violencia policial; otros que brindaban una mirada desde adentro de las protestas y de las acampadas; mash-ups, remixes, slides de fotos, canciones antiguas revividas y vinculadas a las demandas del movimiento; vídeos que vinculaban las protestas en otros 112 lugares del mundo, etc.

Según Kidd (2014), más de 170 mil personas compartieron noticias sobre el OWS, incluyendo vídeos. Uno de los materiales que más llamó la atención y, de cierta forma, ayudó a viralizar mundialmente el Occupy, fue un vídeo en el cual la policía de Nueva York reprimía con spray de pimienta a un grupo de mujeres, durante la marcha del 24 de septiembre (COSTANZA-CHOCK, 2012; KIDD, 2014), además del vídeo-llamado mundial publicado por el grupo Anonymous (COSTANZA-CHOCK, 2012).

Durante el desarrollo de las acampadas, el $29 \%$ de los activistas utilizaba YouTube regularmente como fuente de información, según la encuesta "Occupy activity participation", co-dirigida por Costanza-Chock (2012). Pero un grupo menor, en torno al $8-10 \%$ se dedicaba a la tarea de producir el material audiovisual y compartirlo a través de las redes sociales (COSTANZA-CHOCK, 2012). En la ya citada investigación conducida por Thorson et al. (2013), se tomó una muestra de 1.110 vídeos, cuyos resultados del análisis - que no hacen distinción acerca de la fuente de producción del material, o si se trata de personas comunes, videoactivistas o grandes medios informativos - muestran que la mayor parte de los vídeos son filmaciones de las protestas (30\%); mientras que el $60 \%$ de todo el material analizado es original y el $50 \%$ fue catalogado como material realizado por aficionados.

Es importante señalar que durante el Occupy Wall Street, así como en el 15M, cada acampada solía tener su comisión de comunicación. De esta forma, era natural que surgieran plataformas o movimientos audiovisuales desde dentro de la propia acampada. En el caso del Occupy, la principal herramienta fue el llamado "the global revolution livestream" o la TV de la revolución global (http:// globalrevolution.tv). Esta plataforma 


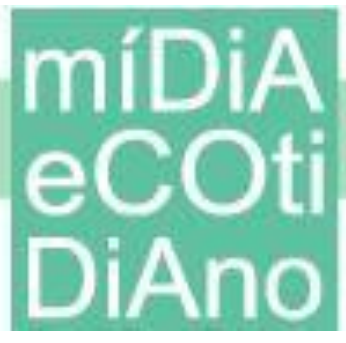

logró aglutinar una gran audiencia en torno a la trasmisión en vivo de las acciones del OWS, llegando a 80 mil espectadores que acompañaban las actividades en vivo, cada día.

Costanza-Schock (2012) llama la atención acerca del hecho de que "GlobalRevolution.tv" fue iniciada por videoactivistas experimentados que habían trabajado en Glassbead Collective (http://glassbeadcollective.org) y Twin Cities Indymedia, en 2008, y que continuaron realizando coberturas de este tipo durante los años siguientes en Nueva York. Entretanto, el autor (COSTANZA-CHOCK, 2012) afirma que las raíces de la experiencia con el streaming en Estados Unidos estarían en la organización The Uptake (http://theuptake.org) y en las primeras experimentaciones realizadas en los años 1980-1990 por Deep Dish TV, durante la cobertura de las protestas anti-nuclear y anti-guerra.

\section{Videoactivismo en las protestas en Turquía}

Mientras grandes protestas tomaban las calles de todo el país y empezaba la ocupación del Park Gezi, la televisión turca emitía programas de cocina y documentales sobre pingüinos. Los activistas empezaron a llamar a los grandes medios de comunicación como "medios pingüino", apropiándose de la figura del pingüino como mascota del movimiento e hicieron un llamado con el hashtag \#BugünTelevizyonlarıKapat/apaga su TV hoy (NILGÜN, 2015). Así, los activistas se dieron cuenta desde el inicio del movimiento que tendrían que crear sus propios medios de comunicación.

Las redes sociales fueron la fuente principal de información sobre las demandas de los activistas que estaban ocupando el Gezi Park, siendo Twitter el más utilizado, seguido por Facebook y YouTube (ÇOBAN; ATAMAN, 2017; NILGÜN, 2015). Lo usuarios de Facebook, entre junio del 2013 y diciembre del mismo año (ZIMMERMAN, 2014) saltaron de 1 millón a 34 millones de perfiles activos. Fueron creados dos grandes grupos en Facebook - Diren Gezi Park y Occupy Gezi, que funcionaban como central de informaciones y organización de los activistas y aquellos que los apoyaban (ZIMMERMAN, 2014). Las redes y formatos mediáticos, así como ocurrió en la mayor parte de las protestas, estaban vinculadas. Una investigación realizada por Boomerang Estambul reveló que más de 7 millones de tweets fueron publicados, utilizando el hashtag \#direngeziparki, resultando en más de 687 mil mensajes que 


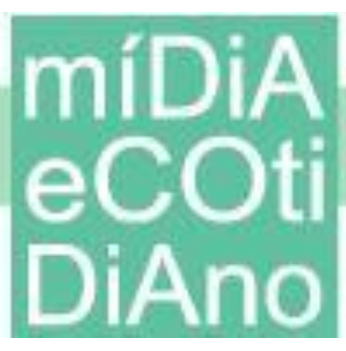

contenían fotos y más de 25 mil que llevaban vídeos enlazados. El mismo estudio también reseña que los mensajes publicados en Facebook ayudaron a viralizar los vídeos y fotos del movimiento (ZIMMERMAN, 2014).

La proliferación de la narrativa desde los activistas fue un fenómeno bastante extendido durante la acampada en Turquía (ÇOBAN; ATAMAN, 2017). Pese a no haber números exactos sobre el porcentaje de manifestantes que la reportaron desde el audiovisual, Nilgün (2015) apunta que, en una encuesta realizada a los participantes de la acampada, el $42 \%$ de los encuestados afirmaron que realizaban sus propios relatos a través de Facebook y Twitter; y el 30\% de ellos usaba YouTube regularmente para informarse sobre el movimiento.

Según Doğanay y Kara (2014), ya en el segundo día de la acampada en el Park Gezi fue montada una comisión de medios, que incluía una coordinación de audiovisual encargada tanto de transmitir las protestas en vivo como de filmarlas y editarlas para después difundir los vídeos a través de las redes sociales. En este momento, los activistas que tenían más experiencia ofrecieron talleres de formación y desde la coordinación de la acampada, a través de la cuenta de Twitter @OccupyGezi ${ }^{6}$, fue realizado un llamado para que todos se empeñasen en crear sus propias narrativas desde adentro para romper el cerco informativo. Así nacieron varios medios y plataformas como la Gezi Radio, los websites "Istanbuldaneoluyor.com, everywheretaksim.net/tr, occupygezivids.tumblr.com, delilimvar.tumblr.com" (DOĞANAY; KARA, 2014) y los grupos de videoactivismo videOccupy ${ }^{7}$, Çekimyapan $\operatorname{Kadinlar}^{8}$, ekipmat,

\footnotetext{
${ }^{6}$ Más información en <https://twitter.com/OccupyGeziNews/> Acceso el 11de mayo de 2017.

${ }^{7}$ La página de fans en Facebook puede ser visitada en $\langle$ https://www.facebook.com/Videoccupy $>$. El canal de YouTube del grupo también puede ser visitado online. Recuperado de <https://www.youtube.com/channel/UCDhtsYy5VC09T0ixjHmhBQQ/feed> Acceso el 11de mayo de 2017.

8 El canal de YouTube del grupo también puede ser visitado online. Recuperado de <https://www.youtube.com/channel/UCMI1ZPcHxvQWUCt8yLMDf5A> Acceso el 11 de mayo de 2017.
} 
Ankaraeylemvakti ${ }^{9}$, ÇapulTv, $^{10}$ y Naber Medya ${ }^{11}$ - que ya existía desde el 2011, pero se sumó a la acampada en este momento.

Una gran parte de los grupos y medios que fueron creados en el contexto de la acampada del Park Gezi dejaron de existir luego del fin del movimiento. Pero ÇapulTv y Naber Medya continuaron sus labores activistas. ÇapulTv fundó una Asociación de medios Alternativos para generar fondos y organizar el trabajo del grupo (AYDOĞAN, 2015). Además, el Colectivo Artıkişler estructuró bak.ma, un gran archivo virtual que pretende organizar y garantizar la memoria audiovisual de los movimientos sociales y políticos del país. Actualmente la plataforma ya cuenta con más de 1.200 vídeos ${ }^{12}$, de los cuales 602 de ellos tiene la acampada de Gezi como temática principal.

\section{EI videoactivismo brasileño: las protestas del 2014}

Las protestas en contra del Mundial de Fútbol de la FIFA, en el 2014, fueron registradas en todas las regiones del país, muchas de las cuales fueron transmitidas en vivo y en directo por las cámaras de los ciudadanos y, principalmente, por colectivos formados por activistas que utilizaban el vídeo como herramienta de lucha. Los grupos videoactivistas aparecieron por todo el país, pero la organización no fue uniforme. Río de Janeiro, además de concentrar el mayor número de protestas, también concentró la mayor cantidad de grupos y colectivos organizados específicamente en torno a la tarea de reportar las protestas desde el audiovisual online. La red videoactivista de esta ciudad se destacó, en grandes rasgos generales, por la: 1) gran cantidad de grupos formados; 2) organización en red; 3) metodología de producción que posibilitaba alta productividad y viralización de los vídeos.

En esta investigación, se relevó los diez grupos con mayor actuación en la ciudad, a saber: Jornal A Nova Democracia, Mídia Ninja, Coletivo Mariachi, Coletivo

\footnotetext{
${ }^{9}$ El canal de YouTube del grupo también puede ser visitado online. Recuperado de < http://www.ustream.tv/channel/ankaraeylemvakti> Acceso el 11de mayo de 2017.

${ }^{10}$ La página de fans en Facebook puede ser visitada en <https://www.facebook.com/CapulTv/ >Acceso el 11 de mayo de 2017. El canal de YouTube del grupo también puede ser visitado online. Recuperado de < https://www.youtube.com/channel/UCiR-XdvDZAPdxtt47UHCzDw> Acceso el 11de mayo de 2017.

${ }^{11}$ Más información en <www.nabermedya.tv > Acceso el 11de mayo de 2017.

${ }^{12} \mathrm{El}$ archivo puede ser visitado en < https://bak.ma/grid/title/list==j:Uploaded\&category==Gezi $>$ Acceso en el 11de mayo del 2017.
} 


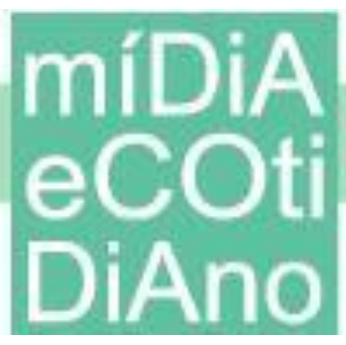

Carranca, Mídia Independente Coletiva, Linhas de Fuga, Coletivo Vinhetando, Coletivo Tatu, Rio40Caos, Cinza Sem Filtro. Estos colectivos no tenían número fijo de miembros y solían ser conformados por entre dos y diez personas. Algunos de ellos ya estaban articulados antes de que estallaran las manifestaciones populares de 2013: Jornal A Nova Democracia, Rio40Caos y Mídia Ninja. Pero la mayor parte de los que protagonizan el estudio aquí presentado nacieron durante el ciclo de protestas en contra del precio de transporte público, en junio de 2013. Una mirada detallada acerca de las prácticas, rutinas productivas y formas organizativas de esos videoactivistas fue objeto de análisis en otro artículo de la autora (SOUSA, 2017).

En relación con el tipo de trabajo realizado, cada colectivo acabó especializándose en un tipo de narrativa, destacándose las notas y reportajes periodísticas, las trasmisiones en vivo, transmitidas por streaming y las imágenes realizadas con función advocacy video, detalladas abajo y profundizadas por la autora en otro trabajo (SOUSA; CERVI, 2017b).

1) notas y reportajes periodísticas en texto, vídeo y fotografía: se centró en la filmación de los eventos, ya sean reuniones, asambleas, protestas, etc., y luego en la composición de una nota o reportaje audiovisual, centrada en el carácter fáctico del suceso. Este material era subido a YouTube y divulgado por Facebook. En este grupo se encontraban: Jornal A Nova Democracia; Mídia Ninja; Colectivo Mariachi; Linhas de Fuga y Mídia Independente Coletiva.

2) streaming: consistió en la trasmisión en vivo, online, de las protestas, asambleas, etc. Los streamers siguen el acontecimiento, no solamente filmando, sino también narrándolos. El hecho de narrar los sucesos transformaba al reportero que se dedicaba a este tipo de trabajo en un camarógrafo y locutor-comentarista de radio, al mismo tiempo. Realizaron este tipo de trabajo: Mídia Ninja y Colectivo Carranca.

3) advocacy vídeo: Aquí se destacaron dos formas de actuación: 1) imágenes captadas para utilización como prueba jurídica, obedeciendo a un protocolo específico que permite que sean validadas legalmente; 2) imágenes captadas para servir "como prueba", pero no necesariamente para la utilización en el ámbito jurídico. En general, las imágenes filmadas bajo la idea del advocacy vídeo no siempre son destinadas a la recepción masiva. En algunas ocasiones, el videoactivista capta las imágenes y después 
las comparte con los abogados para que puedan liberar a manifestantes de encarcelamientos arbitrarios. En los casos en que son utilizadas como prueba de la violación de derechos humanos, suelen ser divulgadas online o insertadas como parte de procesos legales o denuncias frente a cortes nacionales e internacionales. El único grupo dedicado exclusivamente a la realización del advocacy vídeo era el Colectivo Rio40Caos.

La red videoactivista que se formó en Río de Janeiro estuvo compuesta de varios actores - grupos, colectivos o individuos - que se fueron conociendo y conectando a través de la calle y de las redes sociales en Internet. Cada uno de ellos mantenía su independencia como sujetos o colectivos, pero en la práctica, lo que se observó fue una actuación conjunta. Esta red videoactivista desarrolló prácticas mediáticas similares, que fueron construidas como resultado de la práctica callejera y de las propias necesidades del movimiento. Las más importantes desde el punto de vista de la conformación de la red fueron: la actuación callejera como un bloque unido; la organización offline (talleres, reuniones, otras actividades políticas, etc.); la utilización de las redes sociales online como forma organizativa, productiva y de divulgación de los videos; la búsqueda por la viralización de los videos; las jornadas exhaustivas de producción; la creación de criterios de seguridad conjuntos, etc.

El videoactivismo durante la protesta en contra el Mundial de Fútbol de la FIFA tuvo un papel fundamental en la creación de otras narrativas de las movilizaciones. En muchos momentos, llegó a ser apropiada por los grandes medios informativos; mientras en otros, propuso una disputa narrativa con estos medios, como en el caso del encarcelamiento de activistas. Luego del 2013, varios de los colectivos que se formaron en aquel entonces se desintegraron. Pero la experiencia del 2013 pudo influenciar otro movimiento videoactivista muy fuerte en la sociedad brasileña, en el 2015, cuando los estudiantes de las escuelas públicas tomaron sus escuelas y desde las tomas, filmaron todas sus acciones, buscando convencer a la sociedad de la justicia de sus demandas (SOUSA, 2018).

\section{Conclusiones}

Con este recorrido conceptual y práctico del videoactivismo, podemos sugerir que pese a que la literatura académica no haya llegado a un concepto único para nombrar 


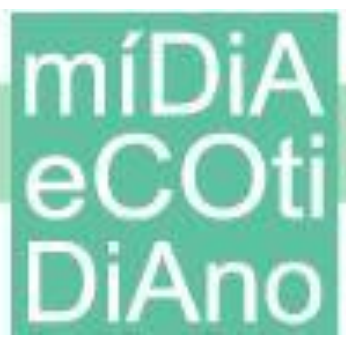

al fenómeno, podemos considerar que lo político es lo fundamental para definirlo. Todos los conceptos que se suelen utilizar pasan por este aspecto, siendo el utilizado por Harding (2001) uno de los más amplios, afirmando que videoactivista es quién utiliza el vídeo como una herramienta táctica para luchar por justicia social. En relación a las prácticas, son muy diversas, utilizando diferentes plataformas y géneros audiovisuales.

Contemporáneamente, el videoactivismo emerge como una importante herramienta para hacer frente tanto a la ausencia de cobertura como al encuadramiento negativo de los movimientos sociales por parte de los grandes medios informativos, en todos los países mencionados en este trabajo. Hay una diferencia significativa en las formas organizativas de los movimientos de protesta que estuvieron basados en acampadas y los que fueron más difusos. En la mayor parte de los casos, las acampadas solían centralizar la producción mediática en torno al movimiento, organizando comisiones de comunicación que tenían la tarea de reportarlo. En donde no hubo acampadas, como en Brasil y en la mayor parte de las protestas de la Primavera Árabe, hubo una mayor fragmentación de la cobertura entre individuales. Siendo que en Brasil se observa la proliferación de grupos organizados específicamente en el calor de las protestas con el objetivo de reportarlas.

En casi todos los países se suele afirmar que fue un fenómeno popular, siendo utilizado largamente por la ciudadanía. No hay datos de la extensión del fenómeno en la mayor parte de los países, entretanto. En el OWS y el 15M, las investigaciones sugieren que cerca del $10 \%$ de los participantes de las acampadas realizaban tareas de media o videoactivismo (COSTANZA-CHOCK, 2012; MONTERDE, 2015). En relación con el tipo de material producido, el streaming fue muy popular en los países de la Primavera Árabe, principalmente Egipto y Túnez; Estados Unidos, Turquía y en Brasil. En España también fue utilizado, pero su uso no fue tan extenso durante las acampadas, de acuerdo con Monterde (2015). Ya los videos subidos a YouTube y compartidos por Facebook fueron utilizados en las protestas en todos los países analizados.

Pensar el videoactivismo comparativamente, tanto mirando la cuestión conceptual como práctica es un paso adelante en el objetivo de comprender el fenómeno más a fondo y acompañar su desarrollo. Nos queda para el futuro reflexionar sobre los cambios provocados con el desplazamiento del activismo a otras redes sociales, como 
Whatsapp y Instagram; además de analizar otros aspectos importantes en la lógica organizativa de estos colectivos, como aspectos de raza, clase, género, territorialidad, etc.

\section{Referências}

ALABAO, N. Videoactivismo 2.0: revueltas, producción audiovisual en torno al $15 \mathrm{M}$ y cultura libre. In: Serrano, E; López, A.C; Monterde, A; Toret, J. 15MP2P. Una mirada transdisciplinar del 15M, 2014. Disponível em: http://tecnopolitica.net/libro15mp2p.> Acesso em: 10 jun. 2017.

ASKANIUS, Tina. Video for Change. In: Wilkins, Karin et al. (Org). The Handbook of Development and Social Change. Oxford: WilleyBlackwell, 2014.

ATTON, Chris. Reshaping Social Movement Media for a New Millennium. Social Movement Studies, V. 2, n 1, p. 2-14, 2003.

AYDOĞAN, A. Çapul TV. In: Kejanhoglu, B. y Scifo, S. Alternative Media and Participation. Transforming audiences, Transforming societies. Working group 2, 2014. Disponível em: <http://www.cost-transformingaudiences.eu/system/files/alternative\%20media\%20and\%20participation-19-02-14.pdf >. Acesso em: 10 jun 2017.

COSTANZA-CHOCK, S. Mic Check! Media Cultures and the Occupy Movement. Social Movement Studies: Journal of Social, Cultural and Political Protest, v. 11, n. 3-4, p. 375385, 2012.

ÇOBAN, B.; ATAMAN, B. The Gezi Resistance and activist citizen reporters.

Communications, v. 42, n. 1, p.1-22, 2017.

COYER, K.; DOWMUNT, T.; FOUNTAIN, A. (2007). The Alternative Media Handbook. London: Routledge, 2007.

DOĞANAY, Uy Kara, I. Video activism in Turkey as a case of alternative media practice: Gezi resistance in focus. In: Kejanhoglu, B. y Scifo, S. Alternative Media and Participation.

Transforming audiences, Transforming societies. Working group 2, 2014. Disponível em: http://www.cost-transformingaudiences.eu/system/files/alternative\%20media\%20and\%20participation-19-02-14.pdf >. Acesso em: 10 jun 2017.

EYZAGUIREE, L. B.; EL AZRAK, S. Videoactivismo y género en la primavera Árabe. In: Sierra, C.; Montero, D. Videoactivismo y Movimientos Sociales. Teoría y praxis de las multitudes conectadas. Barcelona: Gedisa, 2015, p. 233-256.

GITLIN, T. The Whole world is watching: mass media in the making \& unmaking of the New Left. Berkeley: University of California Press, 1980.

HALVERSON, J.R; RUSTON, S.W; TRETHEWEY, A. Mediated Martyrs of the Arab Spring: New Media, Civil Religion and Narrative in Tunisia and Egypt. Journal of Communication, v. 63 n. 2, p. 312-333, 2013.

HARDING, T. The video activist handbook. Pluto Press: London, 2001. 
HOWARD, P. N., et al. Opening closed regimes: what was the role of social media during the Arab Spring?, 2011. Disponível em: https://papers.ssrn.com/sol3/papers.cfm?abstract_id=2595096. Acesso em: 5 set 2019.

JOHANSSON, L. (1999). Participatory Video and PRA: Acknowledging the politics of Empowerment. Forests, Trees and People, Swedish University of Agricultural Sciences, Uppsala, n. 40/41, p. 21-23, 1999.

KIDD, D. The global movement to transform communications. In: Coyer, K.; Dowmunt, T.; and, Fountain, A. The Alternative Media Handbook. London: Routledge, 2007.

KRONA, Michael. Contravigilancia y videoactivismo desde la plaza Tahrir. Sobre las paradojas de la sociedad contravigilante. In: Sierra, C y Montero, D. Videoactivismo y Movimientos Sociales. Teoría y praxis de las multitudes conectadas. Barcelona: Gedisa, 2015, p. 211-232.

LUNCH, C.; LUNCH, N. Insights into Participatory Video. A handbook for the field. Oxford: Insight, 2006.

MAN CHAN, J.; LEE, C. Journalistic "paradigms" of civil protests: a case study in Hong Kong. In: Arno, A. and Dissanayake, W. The News media in national and Internationa conflict. Colorado: Westview Press,1984.

MCLEOD, D. M.; HERTOG, J. K. (1999). Social control, social change and the mass media's role in the regulation of protest groups. In: Demers, D y Viswanath, K. (Org.), Mass media, social control and social change. Ames: Iowa State University Press, p. 305-330.

MATEOS, C.; GAONA, C. Constantes del videoactivismo en la producción audiovisual. Rastreo histórico (1917-2014) y puntualizaciones para una definición. In: Sierra, F. C.; Montero, D. Videoactivismo y movimientos sociales. Teoría y práxis de las multitudes conectadas. Barcelona: Gedisa, 2015.

MATEOS, C.; RAJAS, M. (2014) Videoactivismo: concepto y rasgos. In: Bustos, G. et al (Org). Videoactivismo. Acción política, cámara en mano. Cuadernos Artesanos de Comunicación 71, Tenerife: Universidad de La Laguna.

MONTERDE, Arnau. Emergencia, evolución y efectos del movimiento-red 15M (20112015). Una aproximación tecnopolítica. (tesis de doctorado) - Universidad Oberta de Catalunya, Barcelona, España, 2015.

NILGÜN, M. Cyberactivism 2.0: Determing Social Media Usage in New Social Movements - Twitter and Gezi Resistance in Turkey (thesis for Masters of Arts in Media Studies: Television and Cross-Media Culture). Amsterdam: Universiteit Van Amasterdam, 2015.

PASQUINELLI, Matteo. Mediactivismo (Activismo en los medios). Estrategias y prácticas de la comunicación independiente. Mapa internacional y manual de uso. Roma: DeriveApprodi srl, 2002.

RIOJA, B. P (2014). El streamer, entre el periodismo y ciberactivismo. In: Serrano, E; Sánchez, D. M; MENA, J. C. Sobre las imágenes del 15M. El videoactivismo como experimentación cultural y política. In: Sierra, F.; MONTERO, D. (Eds) Videoactivismo y movimentos sociales. Teoría y práxis de las multitudes conectadas. Barcelona: Gedisa, 2015.

SANCHO, G. R. et. al. Activismo mediático y criminalización de la protesta: medios y movimientos sociales en México. In: SANCHO, G. R. et al. Los movimientos sociales desde la 
comunicación. Rupturas y genealogías. México: Instituto Nacional de Antropología y Historia, 2015.

SEL, S. Comunicación alternativa y politicas publicas en el combate latinoamericano. In: Sel, Susana. La comunicación mediatizada: hegemonías, alternatividades, soberanías. Buenos Aires: Consejo Latinoamericano de Ciencias Sociales - CLACSO, 2009.

SHIRLEY, A. W. Participatory Video: a process that transforms the self and the other. In: Shirley, A. W. (Ed). Participatory Video. Images that Transform and Empower. London: Sage, 2003.

SNOWDEN, P. "Film!": The Arab Revolutions and the Filmmaker as Amanuensis. Visual Anthropology, v. 29, n. 3, 263-277, 2016.

SOUSA, A.L.N. Video Activism: Digital Practices to Narrate Social Movements during the Fifa World Cup (2014). Brazilian journalism research (online), v. 13, p. 38, 2017.

SOUSA, A.L.S; CERVI, Laura. Video activism in the Brazilian protests: Genres, narratives and political participation. Northern Lights: Film \& Media Studies Yearbook, v. 15, p. 69-88, $2017 \mathrm{~b}$.

SOUSA, A.L.S. Metodologías para la escucha en el audiovisual popular. Revista imagofagia, v. 17 , p. $425-448,2018$.

THORSON, K., EKDALE, B. et al (2010). Youtube and Proposition 8. Information, Communication \& Society, v. 13, n. 3, p. 325 - 349, 2010.

WALL, M.; ZAHED, S. I'll be waiting for you guys': A YouTube Call to Action in the Egyptian Revolution. International Journal of Communication, v. 5, p. 1333-1343, 2011.

WALLACK, L et al. Media Advocacy and Public Health. Newbury Park, CA: Sage, 1993.

WELlMAN, B.; RAINIE, L. If Romeo and Juliet Had Mobile Phones. Mobile Media \& Communication, v. 1, n. 1, p. 166-171, 2013.

WIDGINGTON, D. Screening revolution. FAQS about video activism. In: Langlois, Andrea y Dubois, Frédéric (Ed). Autonomous Media. Activating Resistance \& Dissent. Montreal: Cumulus Press, 2005.

WILSON, D.; TANYA, S. Activism and the Ambiguities of Counter-Surveillance. Surveillance \& Society, Kingston, n 8, v. 2, p. 166-180, 2010.

ZARZUELO, M. G. Cine militante y videoactivismo: los discursos audiovisuales de los movimientos sociales. Revista Comunicación, v. 10, p.1091-1102, 2012.

ZIMMERMAN, Ç. The Gezi Park demonstrations 2013: a Case study of Turkey (Thesis for master in International Relations Departament) - Webster University, Vienna, Austria, 2014. 